Article

\title{
Lactobacillus rhamnosus GR-1 ameliorates Trueperella pyogenes-induced barrier dysfunction of bovine endometrial epithelial cells
}

\author{
Ning Liu ${ }^{1}$, Xuan Wu ${ }^{2}$, Meng-Ling Wang ${ }^{3}$, Ya-Nan $\mathrm{Li}^{1}$, Le $\mathrm{Xu}^{1}$, and Yao-Hong $\mathrm{Zhu}^{1, *}$ \\ Ning Liu; nliu2224@163.com \\ Xuan Wu; wuxuanvic@163.com \\ Meng-Ling Wang; wangmengling0@163.com \\ Ya-Nan Li; 13796685756@163.com \\ Le Xu; xlyamiyou@163.com \\ * Yao-Hong Zhu: zhu_yaohong@hotmail.com; Tel.: +86-10-6273-1094
}

\begin{abstract}
Trueperella pyogenes is a common opportunistic pathogen which is one of the main causes of postpartum endometritis in dairy cows. As a substitute for antibiotics, the probiotic Lactobacillus rhamnosus GR-1 has been used in a wide range of clinical treatments. Our experiments were designed to establish a model of anti-damage which LGR-1 was used to protect bovine endometrial epithelial cells (BEECs) from inflammatory damage and cell destruction caused by $T$. pyogenes. Increased expression of NLRP3 inflammasomes and cytokines was observed following T. pyogenes challenge, but this increase was relieved by LGR-1 pretreatment. Immunofluorescence and Western blot analyses revealed that T. pyogenes infection also results in the damage of tight junction proteins in BEECs. The expression levels of Claudin-1, Occludin, and ZO-1 were decreased in cells only infected with T. pyogenes but not in cells pretreated with LGR-1. Moreover, the detection of the anti-apoptotic protein Bcl-2 and apoptotic proteins BAX, cytochrome $c$, as well as the activating effector caspase-3 revealed that T. pyogenes induced apoptosis of BEECs, which was also confirmed by DAPI staining to observe the morphological changes of the nuclei of cell apoptosis and by TUNEL staining to locate the cells undergoing apoptosis. Our data indicate that LGR-1 ameliorates the T. pyogenes-induced barrier dysfunction of BEECs and pre-application of LGR-1 could be an effective strategy for controlling T. pyogenes infection.
\end{abstract}

Keywords: Trueperella pyogenes, bovine endometrial epithelial cells, inflammasome, tight junction, apoptosis, Lactobacillus rhamnosus GR-1

\section{Introduction}

Cow endometritis is a global disease with particularly high incidences in high yielding dairy cows [1, 2]. Postpartum endometritis caused by persistent bacterial infection [3], which has severe impact on the dairy industry and huge economic losses. Presence of pathogenic bacteria in the uterus causes inflammation, histological lesions of the endometrium, and perturbs uterine involution, ovulation and embryo survival [4]. The incidence of uterine infection is associated with the presence of certain bacterial species in the uterus, such as Escherichia coli, Trueperella pyogenes, Fusobacterium spp., and Bacteroides spp [5, 6, 7, 8]. T. pyogenes is considered the most relevant pathogenic bacterium during the development of dairy endometritis due to its persistence in the contaminated uterus, resistance to antimicrobial agents, and synergistic action with Gram-negative bacteria $[9,10]$. Postpartum uterine infection associated with $T$. pyogenes, typically affecting 20 to $40 \%$ of animals after parturition $[11,12,13]$. Previous reports stated that $T$. progenies infects some 
humans who come in close contact with animals $[14,15]$. Of the 31 dairy cows with endometritis in a dairy farm in Beijing in this study, 8 dairy cows were isolated T. pyogenes, with a detection rate of up to $26 \%$, but there was none of $T$. pyogenes was isolated from the other 9 healthy dairy cows.

T. pyogenes could trigger a pro-inflammatory response within the uterus, with transmigration of neutrophils and evidence of mucopurulent discharge $[16,17,18]$. Inflammation is a protective immune response mounted by the evolutionarily conserved innate immune system in response to harmful stimuli, such as pathogens, dead cells or irritants, and is tightly regulated by the host [19]. The NLRP3 inflammasome is activated in response to the widest array of stimuli, leading to the theory that the dissimilar agonists induce similar downstream events that are sensed by NLRP3 [19, 20, 21, 22]. NOD-like receptor NLRP3 inflammasome is a cytoplasmic protein complex that consists of NLRP3, ASC (apoptosis-associated speck-like protein, which contains a caspase recruitment domain) and caspase-1, which has been shown to be a crucial regulator of diverse inflammatory diseases, including type 2 diabetes, atherosclerosis, and inflammatory bowel diseases [23, 24, 25]. The activation of the NLRP3 inflammasome triggers caspase-1 activation [25]. Active caspase-1 subsequently functions to cleave the proinflammatory IL-1 family of cytokines into their bioactive forms, IL-1 $\beta$ and IL-18, and cause pyroptosis, a type of inflammatory cell death [19, 26, 27].

Tight junctions (TJ) regulate ion and macromolecules flux across the epithelium, and also constitute the first barrier that pathogens face during host invasion [28]. The essential components of this epithelial barrier are physical intercellular structures, termed tight junctions, which attach adjacent cells to each other, thereby forming intercellular seals [29, 30, 31]. Claudins, occludin, and junctional adhesion molecules are primary constituents of TJs that are stabilized by the intracellular scaffolding protein zona occludens (ZO) [32,33]. The initial epithelial damage is characterized by TJ opening, reflected as a dramatic drop of transepithelial electrical resistance (TEER) [28, 34, 35].

Apoptosis, the programmed cell death, is finely regulated at gene level resulting in the orderly and efficient removal of damaged cells such as those occurring following DNA damage or during development [37, 38]. Apoptosis occurs normally during development and aging and as a homeostatic mechanism to maintain cell populations in tissues [39]. Apoptosis also occurs as a defense mechanism such as in immune reactions or when cells are damaged by disease or noxious agents [39, 40]. From the morphological point of view apoptotic cells show a characteristic cytoplasmic cell shrinkage, budding of plasma membrane, membrane exposure of phosphatidylserine (PS) on extracellular side, chromatin condensation and DNA fragmentation [38, $41,42]$. It is governed by the BCL-2 family of proteins, which prosurvival BCL-2 proteins (BCL-2, BCL-XL, MCL-1, BCL-W, and A1) maintain cellular viability by directly and indirectly restraining prodeath BAK and BAX, the 2 proteins whose activity define the pathway [43]. BAX and BAK actively induce cytochrome $c$ release from mitochondria within cells and in cell-free systems, both of which are inhibited by anti-apoptotic Bcl-2 family members [44]. The latter triggers the apoptotic caspase cascade, which begins with the initiator caspase, Caspase-9, and culminates in the activation of the effectors, Caspase-3 and Caspase-7 [43].

To date, veterinarians are still limited to antibiotic treatment with $T$. pyogenes infections in many dairy farms in China. However, the issue of antibiotic resistance and food safety are now receiving widespread attention. T. pyogenes is exposed to antimicrobial agents used for growth promotion, prophylaxis, and therapy, notably tylosin, a macrolide antibiotic and the resistance of $T$. pyogenes to tylosin has been documented [45]. Looking for a novel approach for the treatment of $T$. pyogenes infections is our priority. Increasing evidence indicates that probiotics are effective in 
preventing and treating a variety of intestinal disorders through several regulation mechanisms [46]. The probiotic Lactobacillus rhamnosus GG (LGG) may be an adjunct therapy to attenuate and prevent the course of infection, which will allow more judicious use of prophylactic antibiotics and hopefully reduce overall usage [47]. Our previous study showed that probiotic Lactobacillus rhamnosus GR-1 ameliorates E. coli-induced inflammatory damage via attenuation of apoptosis-associated speck-like protein containing a caspase recruitment domain (ASC)-independent NLRP3 inflammasome activation in primary bovine mammary epithelial cells (PBMCs) [48]. However, the use of LGR-1 as a probiotic treatment in protecting cows from postpartum endometritis is rarely reported and the mechanism is still unknown. Using LGR-1 to cure endometritis caused by bacteria provides a significant advantage and requires more energy to study its mechanisms.

The aim of the study is to establish a model of endometrial epithelial cells invaded by clinically isolated T. pyogenes in order to explore the processes and mechanisms of the barrier dysfunction and cell apoptosis and to investigate the potential mechanisms of LGR-1 against T. pyogenes infection.

\section{Materials and Methods}

\subsection{Bacteria}

The 8 clinical T. Pyogenes isolates were collected from uterine lavage fluid using the uterine infusion pipette with an inflated balloon and stainless-steel pins from dairy cows within 15 days postpartum with clinical endometritis. The bacteria were recovered from sheep blood plate medium and a single colony was cultivated in $10 \mathrm{ml}$ brain heart infusion (BHI) broth (Aobox, Beijing, China) at $37^{\circ} \mathrm{C}$ overnight under aerobic conditions. All of the T. pyogenes were harvested by centrifugation and re-suspended twice with Dulbecco's phosphate-buffered saline (PBS; Solarbio, Beijing, China) and counted under the optical microscope.

LGR-1 ATCC 55826 was purchased from the American Type Culture Collection (Manassas, VA, United States) and grown in De Man, Rogosa, and Sharpe (MRS) broth (Aobox, Beijing, China) for $24 \mathrm{~h}$ at $37^{\circ} \mathrm{C}$ under microaerophilic conditions [48]. LGR-1 was inoculated and grown in fresh MRS broth for $8 \mathrm{~h}$ at $37^{\circ} \mathrm{C}$ with the beginning ratio of 1:100 after passing the mid-log phase. The LGR-1 was harvested, re-suspended, and counted as the same method as T. pyogenes. The concentration of LGR-1 was used as $5 \times 10^{7} \mathrm{CFU} / \mathrm{ml}$.

\subsection{Bovine Cell Culture}

For cell culture, BEECs were obtained from the uterine horn and processed as the method previously described [49]. The BEECs were cultured with Dulbecco's Modified Eagle medium/Ham's F-12 medium (1:1) and supplied with 10\% heat-inactivated fetal horse serum, 1\% penicillin and streptomycin (Invitrogen, Carlsbad, CA, United States), respectively. After flowing evenly into cell flasks, the BEECs were cultured at $37{ }^{\circ} \mathrm{C}$ in an incubator with $5 \% \mathrm{CO}_{2}$ atmosphere.

\subsection{Bacterial Growth Curves}

To examine different growth rates of all clinical T. pyogenes isolates and the standard strain, bacterial growth curves were measured for all of $9 \mathrm{~T}$. pyogenes, respectively. Sterilized turbidity tubes were added $1 \mathrm{ml} \mathrm{BHI}$ broth and bacterial solution was dropped until its turbidity is 0.2. $198 \mu \mathrm{l}$ 
of BHI broth was added to each well into a 96-well plate and then $2 \mu \mathrm{l}$ of bacterial solution with a turbidity of 0.5 was added to each well. Each T. pyogenes was repeated three times. The plate was placed in the microplate reader and measured OD600 every hour for a continuously $30 \mathrm{~h}$ measurement.

\subsection{Adhesion Assay}

BEECs were harvested onto six-well cell culture plates. After growing to $80 \%$ full, cells were washed three times with PBS. Cells were pre-incubated with LGR-1 $\left(5 \times 10^{7} \mathrm{CFU} / \mathrm{ml}\right)$ for $3 \mathrm{~h}$. LGR-1 was washed for three times with PBS and cells were then exposed to T. pyogenes $\left(10^{7} \mathrm{CFU} / \mathrm{ml}\right)$ for 9 h. Cells were washed three times with PBS to eliminate non-adherent bacteria and treated with 0.05\% Triton X-100 for $15 \mathrm{~min}$ at room temperature. After harvested by centrifugation for $10 \mathrm{~min}$, cell lysate and cell supernatant were diluted by 10 -fold into 4 concentration gradients and $10 \mu \mathrm{l}$ of each gradient of cell supernatant and lysate were evenly spread on blood plates and for three repeats. Colonies were counted after incubation in a $37^{\circ} \mathrm{C}$ incubator for $48 \mathrm{~h}$.

\subsection{Lactate Dehydrogenase (LDH) Assay}

Different treatments of cells were evaluated with CytoTox 96 Non-Radioactive Cytotoxicity Assay (Promega, Madison, WI, United States) following the instructions of manufacturer. Cells were challenged by T. pyogenes for $9 \mathrm{~h}$ which MOI was 5 for each challenged well. The results were calculated by the following formula: \% cytotoxixity $=$ (sample-control)/(max lysis-correction volume-control+background).

\subsection{Western Blotting}

Cells were pre-incubated with LGR-1 for $3 \mathrm{~h}$ and then exposed with T. pyogenes for $9 \mathrm{~h}$ in six-well cell culture plates as the method mentioned above. After T. pyogenes challenged for $9 \mathrm{~h}$, cells were washed for three times with sterilized PBS and simultaneously extracted for western blot assay. The primary antibodies were rabbit polyclonal anti-ASC (1:500 dilution, 10500-1-AP), rabbit polyclonal anti-claudin-1 (1:2000 dilution, 13050-1-AP), mouse monoclonal anti-ZO-1 (1:1000 dilution, 66452-1-Ig), rabbit polyclonal anti-BAX (1:4000 dilution, 50599-Ig), rabbit polyclonal anti-Bcl-2 (1:1000 dilution, 12789-1-AP), mouse monoclonal anti-caspase-3 (1:1000 dilution, 66470-2-Ig), rabbit polyclonal anti-NLRP3 (1:1000 dilution, 19771-1-AP) (ProteinTech Group, Rosemont, IL), rabbit polyclonal anti-caspase-1 (1:1000 dilution, ab179515), rabbit polyclonal anti-occludin (1:2000 dilution, ab216327) (Abcam), and rabbit polyclonal anti-cytochrome $c$ (1:1000 dilution, 11940S) (Cell Signaling Technology, Danvers, MA). The mouse anti-GAPDH (1:5000 dilution, 60004-1-Ig) and mouse anti- $\beta$-actin (1:5000 dilution, 66009-1-Ig) were applied for verifying the equal sample loading. The secondary antibodies included goat anti-mouse IgG (1:5000 dilution, SA00001-1) or goat anti-rabbit IgG (1:5000 dilution, SA00001-2) (ProteinTech Group). After the films of caspase-1 and caspase-3 were exposure, the films were stripped by Restore Western Blot Stripping Buffer (ThermoFisher, Waltham, MA USA) and re-incubated with primary antibodies for GAPDH or $\beta$-actin. 
Genomic DNA were extracted from T. pyogenes BHI samples by using TIANamp Genomic DNA Kit (Tiangen, Beijing, China) following the instructions of manufacturer. The sequences of primers were used as follow: 27F (5'-AGA GTT TGA TCM TGG CTC AG-3') and 1492R (5'-TAC GGY TAC CTT GTT ACG ACT T-3'). The PCR reaction contents $13 \mu 1$ of $2 \times$ UTaq PCR MasterMix with loading dye (Zoman, Beijing, China), $1 \mu$ l of each of primer, $9 \mu \mathrm{l}$ of PCR water, and $1 \mu \mathrm{l}$ of DNA sample. The virulence genes of each T. pyogenes were detected by PCR amplification. The sequences of primers used are listed in Table 1 . The PCR products were subsequently identified the presence of virulence genes by loading to $2 \%$ agarose gels with $2000 \mathrm{bp}$ marker for electrophoresis and run for $30 \mathrm{~min}$. The gels were pictured by Quick-reference Imaging (Alpha Innotech, San Leandro, CA, USA).

2.8 Scanning electron microscopy (SEM) and transmission electron microscopy (TEM)

Cells were harvested after $9 \mathrm{~h} \mathrm{~T}$. pyogenes infection and fixed with $3 \%$ glutaraldehyde (pH 7.4) for $48 \mathrm{~h}$. Cells were treated with standard SEM and TEM procedures, respectively. SEM was observed and pictured with a Quanta 200 FEG scanning electron microscope (FEI, Eindhoven, the Netherlands) and TEM was observed and pictured with an H-7500 transmission electron microscope (Hitachi, Tokyo, Japan).

\subsection{Quantitative real-time PCR}

Total RNA was isolated by using Trizol reagent (Invitrogen, Carlsbad, CA) from different treatments of BEECs. The concentration of RNA was detected with NanoDrop instrument (ThermoFisher, Waltham, MA USA). RNA was reversed transcription into first-strand cDNA for real-time PCR procedure. The sequences of primers used are listed in Table 2. To normalize the cycle threshold $\left(\mathrm{C}_{\mathrm{T}}\right)$ values, the $\mathrm{C}_{\mathrm{T}}$ values of the hypoxanthine phosphoribosyl-transferase housekeeping genes were evaluated. The data of real-time PCR are exhibited with the method of the $2-\Delta \Delta \mathrm{C}$ as fold-change.

\subsection{Immunofluorescence}

The supernatant was discarded from a 24-well plate with a cell fusion rate of $80 \%$ growing on glass coverslips. With PBS washing three time gently, LGR-1 was pre-applied for $3 \mathrm{~h}$ and cells were then exposed to T. pyogenes for $9 \mathrm{~h}$. Bacteria were washed for three times with PBS. After washing as mentioned above, $500 \mu \mathrm{L}$ of $4 \%$ PFA was added to each well and cells were fixed at room temperature for $10 \mathrm{~min}$. For the next step, $500 \mu \mathrm{L}$ of $1 \%$ Triton X-100 was dropped to per well at room temperature for 15 minutes and washed three times with PBS following with $2 \%$ BSA blocking at room temperature for $1 \mathrm{~h}$. For tight junction experiment, primary antibody (ZO-1, 1:100 dilution) was applied and incubated at $4{ }^{\circ} \mathrm{C}$ overnight and Alexa Fluor 488 goat anti-rabbit as the secondary antibody was applied and incubated in dark at room temperature for $1 \mathrm{~h}$.

For apoptosis experiment, nuclei of cells were stained with DAPI at room temperature for 10 min. Glass coverslips was face down on slides with the anti-fluorescence quencher drip-proof and mounted with neutral resin. Slides were observed and pictured with Nikon A1 confocal laser scanning microscope. 


\subsection{TUNEL}

The BEECs were cultivated on the 24-well cell slides. After the cells were ready for use, the LGR-1 was applied for $3 \mathrm{~h}$ in advance after washing three times gently with PBS. Then, TP1804 was infected the BEECs for $9 \mathrm{~h}$. The apoptosis cells were marked with TUNEL kit from Beyotime (Cat. No.C1806; Beijing, China) following the instructions provided by the manufacturer after the cells were treated as the same method as the immunofluorescence. The Nikon A1 confocal laser scanning microscope was employed for images.

\subsection{Statistical Analysis}

Every experiment was repeated at least for three times which obtained similar outcomes. All data were analyzed by GraphPad Prism 8. The western blotting results were preformed by ImagineJ software and then analyzed by GraphPad Prism 8. All data were preformed with statistical methods of one-way ANOVA and t-test. Multiple corrections were applied by Tukey's honestly significant difference for post hoc test. Data are presented as the mean \pm SEM which were calculated from three similar parallel experiments. A $P$ value of $<0.05$ was considered statistically significant.

\section{Results}

\subsection{Experimental results}

3.1.1 Screening clinical isolates of T. pyogenes based on bacterial growth characteristics

The obvious hemolytic rings and needle-like white colonies were exhibited on a sheep blood medium after the isolated and purified T. pyogenes was cultured at a $37^{\circ} \mathrm{C}$ incubator for $48 \mathrm{~h}$ (Figure 1C). T. pyogenes was observed with strong mobility and high moving speed and the bacteria were short rod-shaped under light microscopy. The length of $T$. pyogenes is $2-3 \mu \mathrm{m}$ and the diameter is $0.5-1 \mu \mathrm{m}$.

The growth curves of 8 isolates of T. pyogenes clinical strains from TP1801 to TP1808 and a standard strain of T. pyogenes ATCC19411 were measured from $0 \mathrm{~h}$ to $30 \mathrm{~h}$ (Figure 1A). The clinical strains TP1804 and TP1806 grew fastest. TP1806 reached its mid-log phase at about $7 \mathrm{~h}$ and entered the plateau phase, while TP1804 passed its mid-log phase at $9 \mathrm{~h}$ and its peak was slightly higher than its of TP1806. The growth curves of the four strains, the standard strain, TP1801, TP1802, and TP1803, were relatively consistent and the growth rates were slow to pass the mid-log phase values which were much lower than the values of TP1804 and TP1806 in approximately 18 hours. The mid-log phase values of TP1805 and TP1807 were still not reached within 27 hours and the mid-log phase value was very low. TP1808 basically had no obvious growth.

The six strains, TP1801 to TP1806, were detected to equip all six virulence genes. Only FimA was not detected in the standard strains, and FimC was not detected in TP1807 and TP1808. The carrying percentage of $\mathrm{PLO}$, fimE, nanH, and nanP in these 9 strains was $100 \%$; the carrying percentage of fimA was $88.9 \%$, and the carrying percentage of fimC was $77.8 \%$ (Table 3 ).

3.1.2 The adhesion of TP1804 to BEECs is reduced by pre-treatment of Lactobacillus rhamnosus GR-1 
Quantitative measurement of lactate dehydrogenase (LDH) method was used to determine the cell mortality after $3 \mathrm{~h}, 6 \mathrm{~h}$, and $9 \mathrm{~h}$ of challenge of T. pyogenes (Figure 1B). The average mortality rates were about $10 \%, 30 \%$, and $40 \%$ at $3 \mathrm{~h}, 6 \mathrm{~h}$, and $9 \mathrm{~h}$, respectively. Comparing $3 \mathrm{~h}, 6 \mathrm{~h}$, and $9 \mathrm{~h}$, it is not difficult to find out that the cell death rates of the standard strain and TP1801 to TP1805 have significantly increased with the extension of time. The mortality of cells challenged by TP1806-TP1808 increased significantly at $6 \mathrm{~h}$, but there was no significant change between $6 \mathrm{~h}$ and 9 h. The mortality of TP1806-TP1808 increased significantly at $6 \mathrm{~h}$, but there was no significant change between $6 \mathrm{~h}$ and $9 \mathrm{~h}$. In each time period, TP1804 had a particularly strong virulence causing the highest cell death rate among all $T$. pyogenes strains. The cell death rates of the standard strains, TP1801, TP1802, and TP1805 were at an intermediate level among all strains and TP1803 caused the the lowest cell mortality. Figure 1E is exhibited as an evidence that TP1804 infection increased the cell death rate significantly, which LGR-1 protection had decreased the cell death rate. However, there was statistic difference between control cells and LGR-1 protected cells.

The number of adherent $T$. pyogenes was $1.63 \times 10^{4} \pm 2.08 \times 10^{3} \mathrm{CFU}$ (means $\pm \mathrm{SEM}$ ) after BEECs were exposed to TP1804 (Figure 1D). With the LGR-1 was pre-applied to BEECs, the number of adherent $T$. pyogenes was statistically significant decreased, which the number was $6.9 \times 10^{3} \pm 6.56 \times$ $10^{2}$ CFU (means \pm SEM). Both T. pyogenes and LGR-1 adhere to the surface of BEECs. Pre-incubation LGR-1 before $3 \mathrm{~h}$ of TP1804 challenge demonstrated, compared with TP1804 treated alone, the adhesion rate of TP1804 was reduced nearly $60 \%$, which is indicating that LGR-1 significantly inhibited a certain extent of adhesion of T. pyogenes to BEECs.

\subsubsection{Lactobacillus rhamnosus GR-1 attenuates the BEECs damage caused by T. pyogenes}

In order to observe the changes in cell morphological structure and the degree of damage to cells produced by $T$. pyogenes, the pictures of cellular changes after challenge $9 \mathrm{~h}$ were taken by general light microscope (Figure 2C). Cells with no treatment clearly exhibited typically polygonal epithelial cell characteristics which were evenly tiled on the same layer with complete morphology and very tightly connected. In TP1804 treated cells, bacterial membranes were not easily washed away and short rod-shaped bacteria were seen moving fast. Cell rupture, death, and shedding were easily observed and about $50 \%$ to $60 \%$ of the cells fell off. Large gaps, loose arrangement, cell morphology change, vacuolization, breakage of cell membrane integrity, and the nucleus shrinkage and deformation were captured with the light microscope. Meanwhile, the cells with LGR-1 pre-applied for $3 \mathrm{~h}$ were much improved in morphological changes. The cell rupture and cell death were mitigated and the shape maintained cobblestone shaped polygon with tight connection between cells. Cells with LGR-1 treated only had with similar conditions as control cells.

The cell surface damage caused by TP1804 after $9 \mathrm{~h}$ infection and the protective effect of LGR-1 on cell damage were observed and imagined via scanning electron microscope (Figure 2A). The outline of the cell construction was complete and the cell membrane was smoother with filamentous substance connections between cells without any treatment. Cells connect tightly and there was no damage found. However, the cells infected by TP1804 were shrunk and the integrity of cells was ruptured which reflects in cell membrane broken and cell contents extravasated. The intercellular gap was increased and the interstitial filaments were fractured. The cells with LGR-1 protection were found that the degree of cell shrinkage was relieved compared with the cells infected by TP1804. Compared with TP1804 challenged cells, individual cell membrane was slightly 
damaged and filamentous substances were still visible between cells. Meanwhile, there was no obvious difference between cells only affected by LGR-1 and the control. The cell outline was complete and tightly connected.

Cell internal structure after $9 \mathrm{~h}$ of TP1804 infection and protective effects of LGR-1 on cell damage were executed via a transmission electron microscope (Figure 2B). The morphology and structure of untreated cells were complete. A large number of intact microvilli were visible on the cell membrane surface and the tight junction proteins between cells were clear and complete. The electron density in the cytoplasm and the mitochondrial outline structure were seen relatively uniform and complete. Nuclear morphology is regular without shrinking and nuclear envelope was clear. The morphology and structure of the cells challenged by TP1804 were blurred and microvilli were not visible on the cell membrane surface. A large amount of cell content leaked out of the cytoplasm. The tight junction proteins between cells were bent, darkened, and severely broken. Mitochondria were critically damaged and the endoplasmic reticulum was circulated. Obvious vacuole-like change and shrinkage occur in nuclei accompanied with nuclear envelope contour blurry and the fusion of nucleus and cytoplasm were observed. The cells protected by LGR-1 still maintained a certain degree of complete morphological structure and the microvilli was still visible on the cell surface. Structure and morphology of mitochondria and endoplasmic reticulum remained valuable. It was more uniform in electron density in the cytoplasm and the tight junction proteins between cells were clearer compared with cells challenged by TP1804. More importantly, the condition of nucleus mentioned above has been alleviated considerably.

3.1.4 Pre-treatment of Lactobacillus rhamnosus GR-1 suppresses the activation of NLRP3 and ASC inflammasomes in BEECs infected by T. pyogenes

In order to investigate whether LGR-1 is able to reduce the inflammatory responses caused by T. pyogenes, this experiment used western blotting to quantitatively analyze the tightly linked inflammatory proteins in BEECs, including ASC, NLRP3, and caspase-1 (Figure 3A-C). As shown in Figure 3A, the expression level of NLRP3 in the cells infected by TP1804 was significantly up-regulated compared with that in control cells $9 \mathrm{~h}$ after challenge $(\mathrm{P}<0.01)$. However, the expression of NLRP3 in cells treated by LGR-1 alone had a slight increase compared with that of control cells. Upon the TP1804 challenge, the expression of NLRP3 in the cell protected by LGR-1 was significantly reduced $(\mathrm{P}<0.001)$, which had no statistic difference as that of control cells. As shown in Figure 3B, the expression of ASC was significantly up-regulated in cells after TP1804 challenge for $9 \mathrm{~h}$ compared with control cells $(\mathrm{P}<0.001)$, while there was no significant increase in the cells treated by LGR-1 alone compared with control cells. Comparing with the cells challenged by TP1804, the expression of ASC in the cells protected by LGR-1 was significantly reduced (P $<0.001$ ) and basically consistent with the cells treated by LGR-1 only. The expression of caspase- $1 \mathrm{p}$ 10 protein was also significantly increased in the TP1804 challenged cells $(\mathrm{P}<0.001)$ (Figure 3C). In contrast, the expression level of caspase- 1 p 10 protein in the cells protected by LGR-1 was considerately reduced $(\mathrm{P}<0.001)$ and was slightly higher than that in control cells.

In order to investigate whether LGR-1 is capable to ameliorate the inflammatory responses caused by T. pyogenes, qPCR was used to quantitatively analyze cytokines in BEECs. After the cells were challenged by TP1804 for $9 \mathrm{~h}$, the expression levels of IL- $1 \alpha$, IL-1 $\beta$, IL-8, CXCL-1/2 were all increased significantly (Figure 3D-G). There were slight changes in the cells treated by LGR-1 alone 
among these factors. Compared with the cells challenged by TP1804, cells with the protection of LGR-1 had a significant decrease and were higher than these factors in control cells except for the CXCL-1/2 factor which was lower than that in control cells without statistical difference (Figure 3F). With the TP1804 challenge, the expression levels of TNF- $\alpha$ and CXCL-3 in BEECs increased compared with control cells after $9 \mathrm{~h}$ treatment. However, the expression of these two factors in cells challenged by TP1804 did not show statistically significant modulated compared with these factors in control cells (Figure 3H, I).

3.1.5 Pre-treatment of Lactobacillus rhamnosus GR-1 reduces the disruption of tight junctions in BEECs infected by T. pyogenes

In order to investigate whether LGR-1 is bale to improve the damage of tight junction structures caused by T. pyogenes, western blotting was used to quantitatively analyze the expression of tight junction proteins in BEECs, including ZO-1, Claudin-1, and Occludin (Figure 4A-C). As shown in Figure 4A, the expression of Occludin in the BEECs challenged by TP1804 was significantly lower than that in control cells in $9 \mathrm{~h}$ after challenge $(\mathrm{P}<0.01)$. LGR-1 alone treated cells had a slight decrease compared with control cells. Compared with the cells challenged by TP1804, the expression of Occludin in the LGR-1 protected cells increased significantly, but it was still lower than that control cells.

The expression of Claudin-1 in BEECs infected by TP1804 was significantly lower than that in control cells after $9 \mathrm{~h}$ challenge $(\mathrm{P}<0.05)$ (Figure 4B). Compared with control cells, the expression of Claudin-1 in the cells treated by LGR-1 alone showed a slight increase without significant difference. The expression of Claudin-1 in the LGR-1 protected cells was significantly higher than the cells infected by TP1804, and was slightly higher than that in control cells.

As shown in the Figure 4C, the expression of ZO- 1 was significantly reduced in the TP1804 challenged cells after $9 \mathrm{~h}(\mathrm{P}<0.01)$. Compared with control cells, the expression in only LGR-1 treated cells had no significant decrease. Compared with the infected cells, the expression of ZO-1 in the LGR-protected cells increased significantly ( $\mathrm{P}<0.01)$, which was basically the same as that in control cells.

Immunofluorescence staining of tight junction protein ZO-1 was performed using cell climbing slides and pictured under a confocal inverted microscope (Figure 4D). In control cells, a complete green fluorescent bright band is able to be seen along the cell membrane. Compared with control cells, ZO-1 in the TP1804 challenged cells was severely damaged. Occasionally, there were intermittent green fluorescent bright dots around the cell membrane. Compared with the TP1804 challenged cells, the damage of the probiotic protected cells has improved to a certain extent, and a more complete green fluorescent bright band was seen. The expression of ZO-1 in the cells protected by LGR-1 was not significantly damaged compared with control cells, and a more complete green fluorescent bright band was visible.

3.1.6 Pre-treatment of Lactobacillus rhamnosus GR-1 decreases apoptosis of BEECs infected by T. pyogenes

In the study of apoptosis caused by T. pyogenes to cells, western blotting was executed to detect proteins that are closely related to apoptosis, including BAX, Bcl-2, caspase-3, and cytochrome $c$. In Figure 5A, the expression of BAX in the TP1804 challenged cells was obviously up-regulated 
compared with control cells and LGR-1 protected cells with statistically significant difference. In Figure 5B, the expression of Bcl-2 in the TP1804 challenged cells was down-regulated significantly compared with control cells. The relative amount of Bax is higher than Bcl-2. However, the expression of LGR-1 protected cells was higher than that in the cells challenged by TP1804 without statistically significant difference. Moreover, the expression levels of the caspase-3 p 19 protein and cytochrome $c$ were increased significantly distinguished between the TP1804 treated cells and control cells. The LGR-1 had down-regulated the effects of apoptosis caused by T. pyogenes with $\mathrm{P}$-value $<0.01$. However, LGR-1 had no significant influences on the expression of the caspase-3 $\mathrm{p}$ 19 protein caused by T. pyogenes (Figure 5C-E).

The pictures are exhibited the DAPI staining of nuclei of BEECs (Figure 5F). In the TP1804 infected cells, the nuclei were shrank and deformed to form an irregular shape with empty spots compared with control cells. The TUNNEL staining was applied for confirming the BEECs apoptosis caused by T. pyogenes and the effects of LGR-1 against the T. pyogenes on attenuating the cell apoptosis (Figure 5G). The photos show that the apparent apoptosis in the TP1804 infected cells which nuclei are bright and irregular due to the treatment of T. pyogenes.

\subsection{Figures and Tables}



a

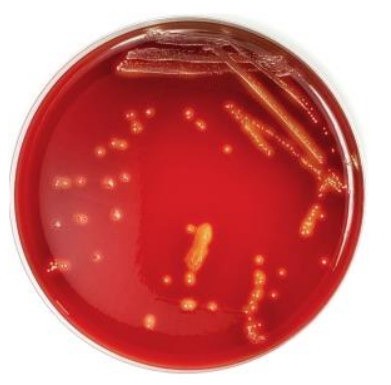

c

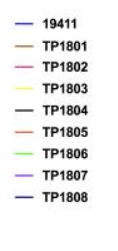

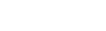

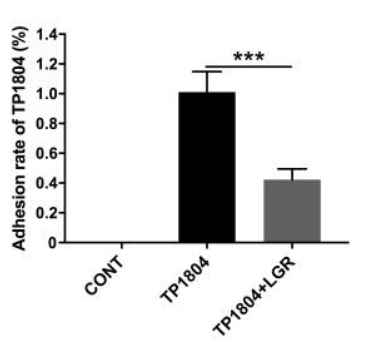

d



b

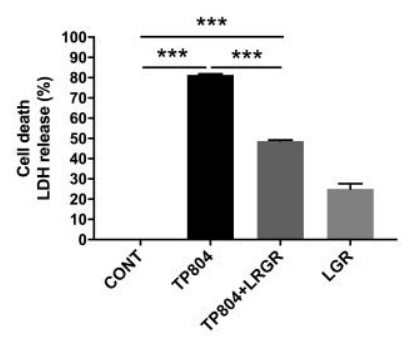

e

Figure 1 Growth and virulence testing of T. pyogenes. (A) Comparison of growth curve results within 27 hours among clinical isolates and the standard strain of T. pyogenes. (B) Comparison of cytotoxicity of all T. pyogenes strains on cells at 3h, $6 \mathrm{~h}$ and $9 \mathrm{~h}$. (C) Growth of TP1804 on blood plate medium for $24 \mathrm{~h}$. Bacteria are punctate and have hemolytic rings around. (D) BEECs were harvested after Lactobacillus rhamnosus GR-1 pre-protected for $3 \mathrm{~h}$ and T. pyogenes treated $9 \mathrm{~h}$. The adhesion rates were the numbers of adhered T. pyogenes with and without Lactobacillus rhamnosus GR-1 pre-treated. (E) Comparison of the cytotoxicity of T. pyogenes on cells directly in $9 \mathrm{~h}$ and the cytotoxicity of T. pyogenes after Lactobacillus rhamnosus GR-1 protection in advance. The mean \pm SEM of data was shown from three independent repeat. $\left({ }^{*} \mathrm{P}<0.05,{ }^{* *} \mathrm{P}<0.01,{ }^{* * *} \mathrm{P}<0.001\right)$ 


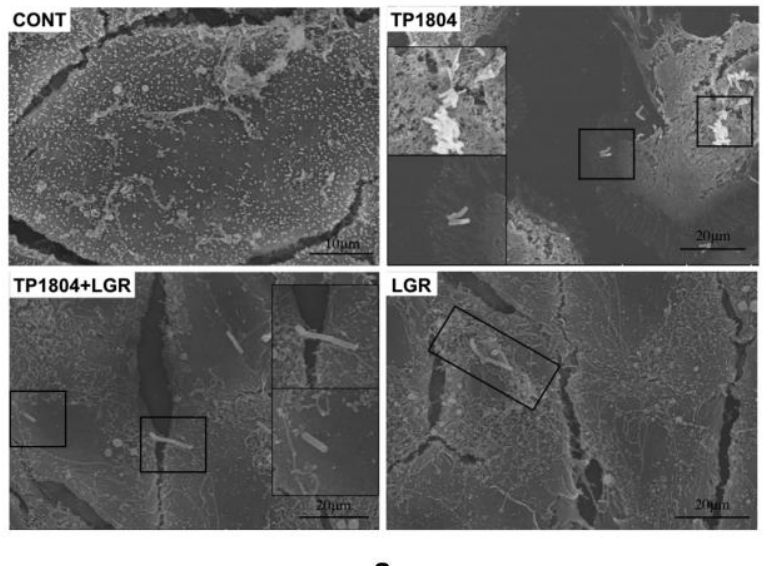

a

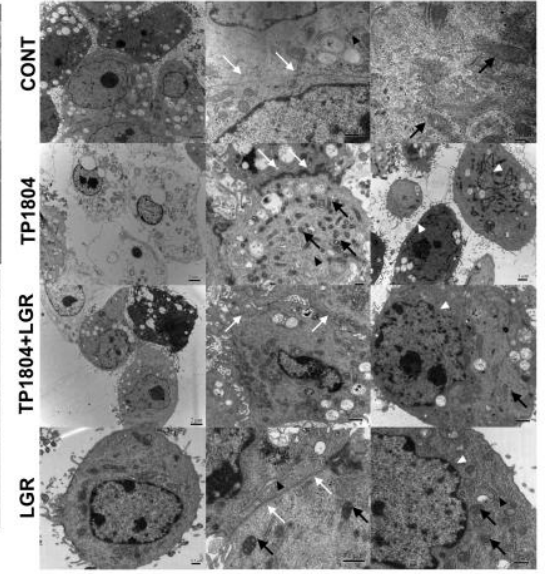

b

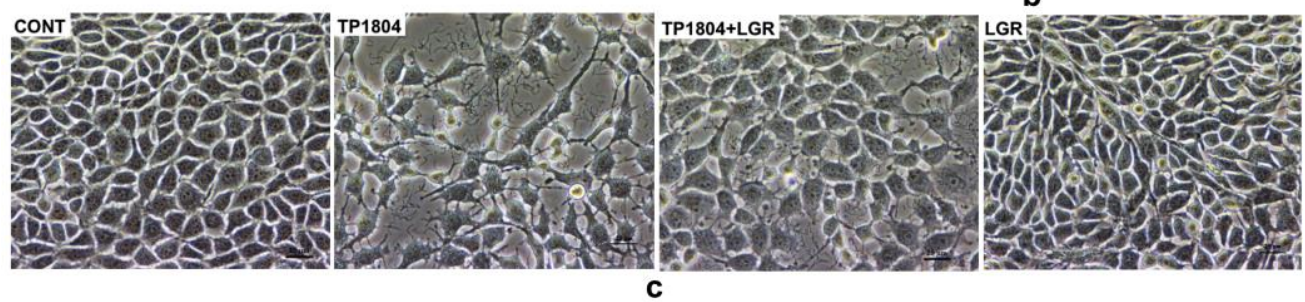

Figure 2 Observation of cells with Lactobacillus rhamnosus GR-1 pre-protection reduces the destruction of ultrastructural structure damage caused by T. pyogenes using SEM (A), TEM (B), and optical microscope (C). The surface of cells without any bacterial infection, the damage of cells after $9 \mathrm{~h}$ of T. pyogenes infection and the protection effects of LGR-1 are compared (A). Cells were severely ruptured and the cell microvilli was broken. Cells were protected with Lactobacillus rhamnosus GR-1 for $3 \mathrm{~h}$ in advance and then infected with T. pyogenes for $9 \mathrm{~h}$. The cell status was significantly improved compared with the cells in TP1804 challenged cells. Lactobacillus rhamnosus GR-1 and T. pyogenes were in black frames. In (B), white arrows indicate tight junction proteins; black arrows indicate mitochondria; black triangles indicate endoplasmic reticulum; white triangles indicate nuclear membrane. Normal morphology of cells are shown without infection by bacteria under optical microscope $(\mathbf{C})$. After $9 \mathrm{~h}$ of infection by T. pyogenes, the cells appeared stringed and deformed, and a large number of cell death. The status of cells protected by Lactobacillus rhamnosus GR-1 for $3 \mathrm{~h}$ before infection with T. pyogenes was much improved compared with that in TP1804 challenged cells. The status of cells treated by probiotic alone was basically the same as that of control cells. 

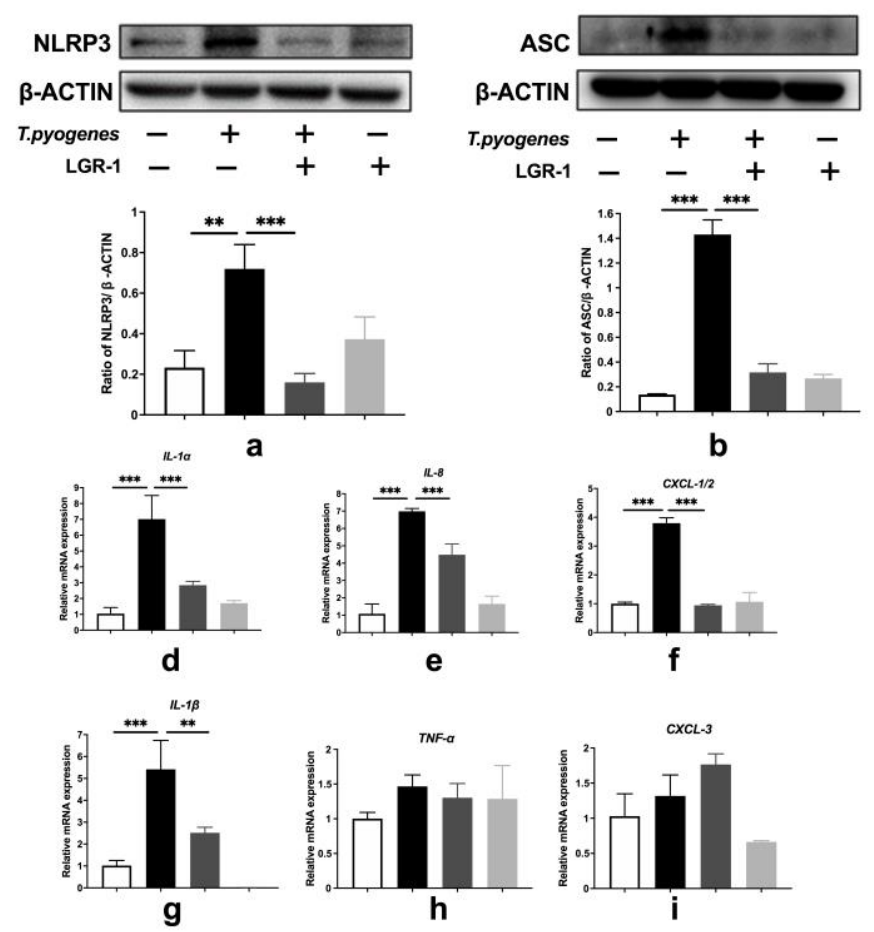
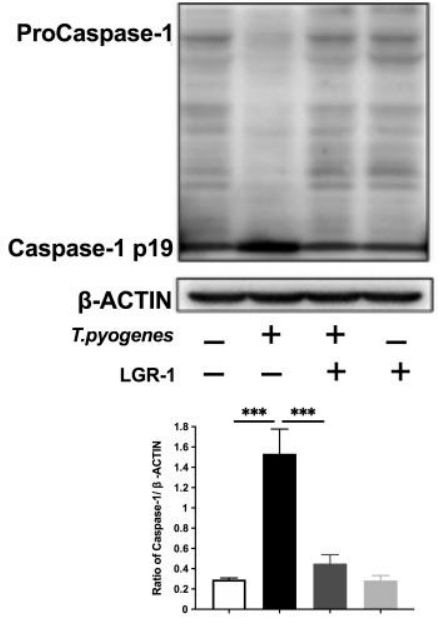

C

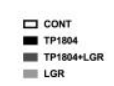

Figure 3 Application of Lactobacillus rhamnosus GR-1 in advance limited the extent of T. pyogenes to activate cellular inflammasomes and cytokines. Western blot analysis of NLRP3 (A), ASC (B), and caspase-1 (C) expression results after $9 \mathrm{~h}$ of T. pyogenes infection on BEECs and the protection of Lactobacillus rhamnosus GR-1. The mRNA expression levels of IL-1 $\alpha$ (D), IL-8 (E), CXCL-1/2 (F), IL-1 $\beta$ (G), TNF- $\alpha$ (H), CXCL-3 (I) of T. pyogenes infection to BEECs after $9 \mathrm{~h}$. Lactobacillus rhamnosus GR-1 was protected $3 \mathrm{~h}$ in advance of T. pyogenes infection. The mean \pm SEM of data is shown from three independent repeat. $\left({ }^{*} \mathrm{P}<0.05,{ }^{* *} \mathrm{P}<0.01,{ }^{* * *} \mathrm{P}<0.001\right)$.

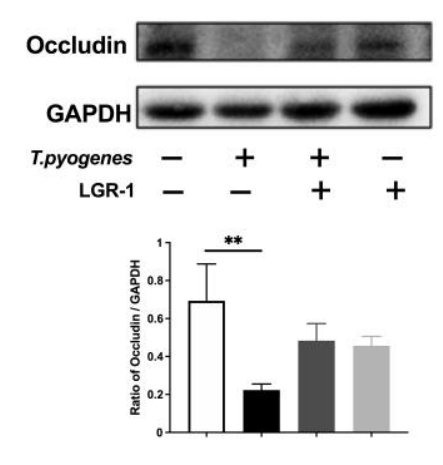

a

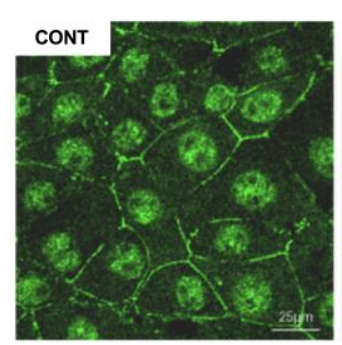

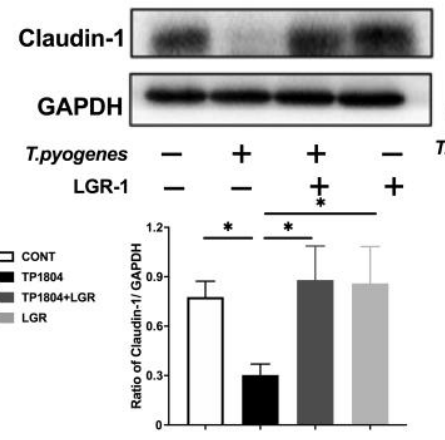

b

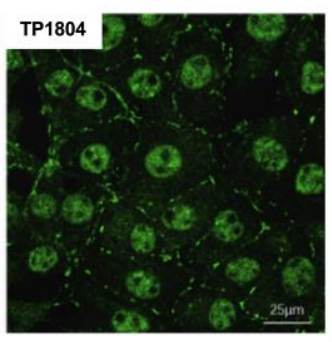

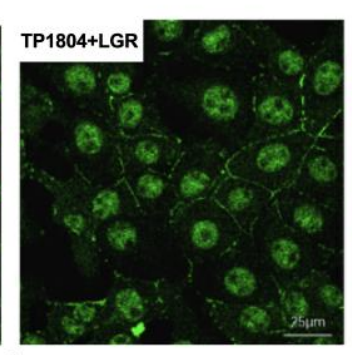

d

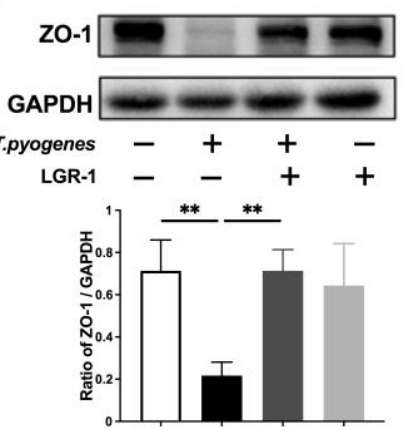

C

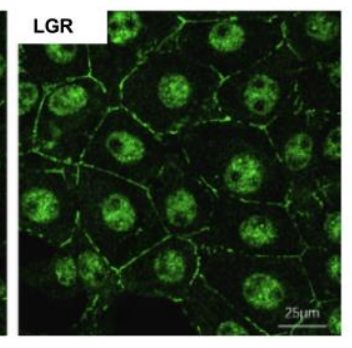

Figure 4 Protective effects of Lactobacillus rhamnosus GR-1 inhibited the destruction of tight junction proteins caused by T. pyogenes. The western blot analysis of Occludin (A), Claudin-1 (B), and ZO-1 (C) of BEECs infected by T. pyogenes for $9 \mathrm{~h}$ and the protection of Lactobacillus rhamnosus GR-1 $3 \mathrm{~h}$ in advance. In (D), the 
immunofluorescence photographs show comparison of tight junction protein ZO-1 in T. pyogenes destruction and Lactobacillus rhamnosus GR-1 protection. T. pyogenes was exposed to BEECs for $9 \mathrm{~h}$ and Lactobacillus rhamnosus GR-1 was applied $3 \mathrm{~h}$ in advance in the protected cells. The mean \pm SEM of data was shown from three independent repeat. $\left({ }^{*} \mathrm{P}<0.05,{ }^{* *} \mathrm{P}<0.01,{ }^{* * *} \mathrm{P}<0.001\right)$
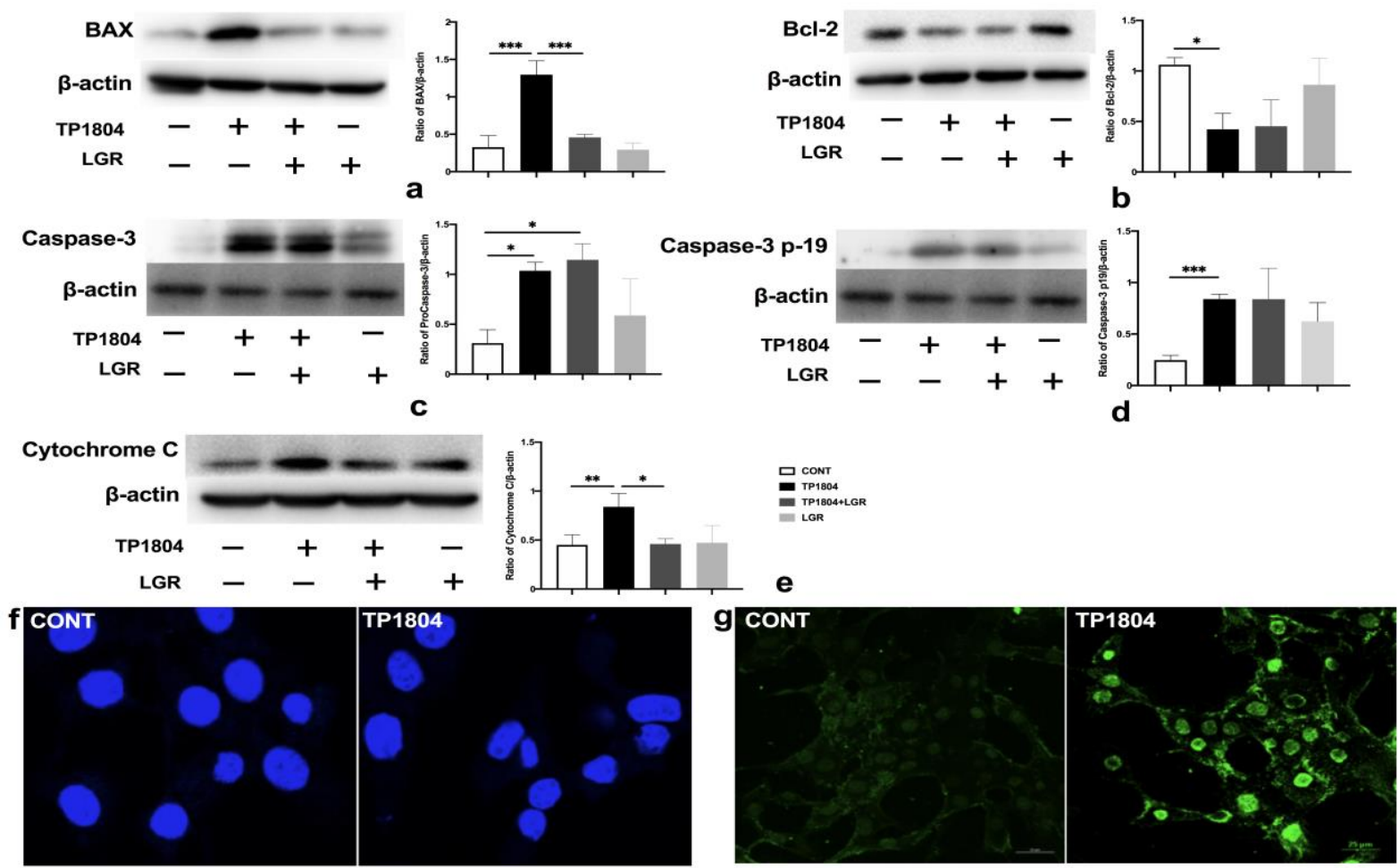

Figure 5 Through Lactobacillus rhamnosus GR-1 protection in advance, the number of apoptotic cells caused by T. pyogenes and the symptoms of apoptosis significantly reduced. The western blot analysis of BAX (A), Bcl-2 (B), caspase-3 (C) p-19 (D), and cytochrome $c$ (E) of BEECs infected by T. pyogenes after 9 h. Lactobacillus rhamnosus GR-1 was applied to BEECs $3 \mathrm{~h}$ in advance. The results show that apoptosis induced by T. pyogenes is notable and Lactobacillus rhamnosus GR-1 had a significant protective effect to reduce the expression levels of apoptosis-related proteins. The results of DAPI staining $(\mathbf{F})$ and TUNEL staining $(\mathbf{G})$ show the notable apoptotic differences of the nuclei in control cells and the T. pyogenes infection cells. The mean \pm SEM of data is shown from three independent repeat. $\left({ }^{*} \mathrm{P}<0.05,{ }^{* *} \mathrm{P}<0.01,{ }^{* * *} \mathrm{P}<0.001\right)$

Table 1. Sequencing of virulence gene primers

\begin{tabular}{lll}
\hline Primer name & Direction & Sequence $\mathbf{( 5}^{\prime} \mathbf{3}^{\prime} \mathbf{)}$ \\
\hline nanH & $\mathrm{F}$ & CGCTAGTGCTGTAGCGTTGTTAAGT \\
& $\mathrm{R}$ & CCGAGGAGTTTTGACTGACTTTGT \\
$\operatorname{nanP}$ & $\mathrm{F}$ & TTGAGCGTACGCAGCTCTTC \\
& $\mathrm{R}$ & CCACGAAATCGGCCTTATTG \\
PLO & $\mathrm{F}$ & TCATCAACAATCCCACGAAGAG \\
& $\mathrm{R}$ & TTGCCTCCAGTTGACGCTTT \\
$\operatorname{cbpA}$ & $\mathrm{F}$ & GCAGGGTTGGTGAAAGAGTTTACT \\
& $\mathrm{R}$ & GCTTGATATAACCTTCAGAATTTGCA \\
Fim-A & $\mathrm{F}$ & CACTACGCTCACCATTCACAAG \\
& $\mathrm{R}$ & GCTGTAATCCGCTTTGTCTGTG \\
Fim-C & $\mathrm{F}$ & TGTCGAAGGTGACGTTCTTCG \\
& $\mathrm{R}$ & CAAGGTCACCGAGACTGCTGG \\
Fim-E & $\mathrm{F}$ & GCCCAGGACCGAGAGCGAGGGC \\
\hline
\end{tabular}




\begin{tabular}{lll}
\hline & $\mathrm{R}$ & GCCTTCACAAATAACAGCAACC \\
Fim-G & $\mathrm{F}$ & ACGCTTCAGAAGGTCACCAGG \\
& $\mathrm{R}$ & ATCTTGATCTGCCCCCATGCG \\
\hline
\end{tabular}

Table 2. Sequences of oligonucleotide primers used for real-time PCR

\begin{tabular}{|c|c|c|}
\hline Primer name & Direction & Sequence $\left(5^{\prime}-3^{\prime}\right)$ \\
\hline \multirow[t]{2}{*}{ GAPDH } & $\mathrm{F}$ & GTCTTCACTACCATGGAGAAGG \\
\hline & $\mathrm{R}$ & TCATGGATGACCTTGGCCAG \\
\hline \multirow[t]{2}{*}{ IL- $1 \alpha$} & $\mathrm{F}$ & TCATCCACCAGGAATGCATC \\
\hline & $\mathrm{R}$ & AGCCATGCTTTTCCCAGAAG \\
\hline \multirow[t]{2}{*}{ IL-1 $\beta$} & $\mathrm{F}$ & GGCCGCCAAGATATAACTGA \\
\hline & $\mathrm{R}$ & GGACCTCTGGGTATGGCTTTC \\
\hline \multirow[t]{2}{*}{ IL-8 } & $\mathrm{F}$ & ACACATTCСАСАССТТТССАС \\
\hline & $\mathrm{R}$ & ACCTTCTGCACCCACTTTTC \\
\hline \multirow[t]{2}{*}{ TNF- $\alpha$} & $\mathrm{F}$ & GCCCACGTTGTAGCCAATGTCAAA \\
\hline & $\mathrm{R}$ & GTTGTCTTTCAGCTTCACGCCGTT \\
\hline \multirow[t]{2}{*}{ CXCL1/2 } & $\mathrm{F}$ & GACCTTGCAGGGGATTCACCTC \\
\hline & $\mathrm{R}$ & GGTTGAGACACACTTCCTG \\
\hline \multirow[t]{2}{*}{ CXCL-3 } & $\mathrm{F}$ & GCCATTGCCTGCAAACTT \\
\hline & $\mathrm{R}$ & TGCTGCCCTTGTTTAGCA \\
\hline
\end{tabular}

Table 3. Detection of virulence genes of T. pyogene

\begin{tabular}{|c|c|c|c|c|c|c|}
\hline Strain & FimA & fimC & FimE & nanH & nanP & plo \\
\hline АСТТ19411 & - & + & + & + & + & + \\
\hline ТP1801 & + & + & + & + & + & + \\
\hline ТP1802 & + & + & + & + & + & + \\
\hline ТP1803 & + & + & + & + & + & + \\
\hline TP1804 & + & + & + & + & + & + \\
\hline TP1805 & + & + & + & + & + & + \\
\hline TP1806 & + & + & + & + & + & + \\
\hline ТP1807 & + & - & + & + & + & + \\
\hline ТP1808 & + & - & + & + & + & + \\
\hline
\end{tabular}

\section{Discussion}

T. pyogenes is considered to be closely associated with purulent uterine mucus. All T. pyogenes clinical isolates in this study were derived from uterine lavage fluid of cows with endometritis. $E$. coli was isolated from the uterine lavage fluid of both healthy cows and cows with endometritis, further explaining that the properties of uterine secretions are related to T. pyogenes but not related to E. coli. Indeed, no T. pyogenes has been isolated from healthy cows. However, T. pyogenes enters the uterus of cows with weak resistance or disordered bacteria and becomes the dominant bacteria, which causes cows endometritis. This phenomenon further proves that T. pyogenes is closely related to the occurrence of endometritis in dairy cows rather than $E$. coli. The high isolation rate of $T$. pyogenes from cows with endometritis and its relationship with purulent uterine mucus in this 
study also indicate the importance of $T$. pyogenes in the etiology of endometritis. However, $T$. pyogenes is not the only factor in the cow uterine infection. To some extent, diseased cows may be infected with more than one pathogenic bacteria, and the interaction of pathogenic microorganisms may also promote the development of endometritis.

The restriction of LGR-1 to T. pyogenes is a complex and comprehensive process. Based on our experiment, the LGR-1 as probiotic has the capability to reduce nearly $60 \%$ of the adhesion of $T$. pyogenes, thereby to extenuate the cell destructions caused by T. pyogenes. The further effects of LGR-1 are to inhibit the T. pyogenes-induced cellular inflammasome responses and the destructions of cell ultra-structure, thereby reducing the occurrence of cell apoptosis.

The expression of inflammatory factors in the cells protected by LGR-1 was significantly suppressed, indicating that LGR-1 significantly alleviated the over-expression of inflammatory factors caused by T. pyogenes. The anti-inflammatory effect of LGR-1 may be related to the lactic acid produced by itself. Lötscher et al. reported that in vivo tests of pancreatitis and acute hepatitis in mice, intraperitoneal and subcutaneous injection of appropriate amounts of lactic acid can significantly reduce the inflammatory response [50]. The presence of LGR-1 inhibited the protein expression of the NLRP3 inflammasome pathway, thereby alleviating the inflammatory damage caused by T. pyogenes to a certain extent. Hoque et al. showed that after lactic acid has bound to the G protein coupled receptor GPR81 protein, it inhibits NLRP3 activation and IL-1 $\beta$ expression through negative feedback regulation [51]. TNF- $\alpha$ and CXCL-3 showed a slight increase with no significant change in expression after TP1804 challenge. In vitro [16[ and in vivo [52] studies provided evidence that CXCL3 plays a integrative role in uterine inflammation in cows [53]. Nevertheless, the biological significance of CXCL3 is not fully understood, as CXCL3 is constitutively secreted by epithelial cells also in the absence of inflammation [54].

NLRP3 is activated by a wide variety of stimuli, including pore-forming toxins, extracellular adenosine triphosphate, RNA-DNA hybrid molecules, and pathogens [55]. Caspase-1 is thought to be activated by a proximity-induced dimerization and autoproteolytic process in the NLRP3/ASC complex platform [56]. Active caspase-1 cleaves pro-IL-1 $\beta$ and pro-IL-18 into mature IL-1 $\beta$ and IL-18, which are essential for coordination of immune responses to pathogen infection through allograft neutrophil sequestration, mononuclear phagocyte recruitment, and T-cell activation [57]. In this study, we also found the high connectivity of inflammatory proteins and inflammatory factors. The previous studies in our laboratory have shown that Lactobacillus rhamnosus GR-1 inhibited ASC-dependent NLRP3 activation, thereby improving inflammatory damage caused by E. coli [58]. A major challenge is to identify as early as possible the precise molecular mechanisms that regulate normal inflammation in healthy animals and those which signal pathological inflammation in cattle susceptible to clinical endometritis [2]. In this study, the expression of ASC, NLRP3, and caspase-1 quantitatively detected by western blotting was increased significantly after $9 \mathrm{~h}$ of TP1804 challenge. Application of LGR-1 in advance significantly decreased the expression of inflammatory proteins and relieved the inflammatory damage of cells. It shows that the model of endometrial inflammation induced by T. pyogenes in BEECs is successful and LGR-1 is able to effectively relieve inflammatory damage. Furthermore, the expression of cytokine mRNA was detected by qPCR also demonstrating that the downstream pathway of inflammatory damage of cells is related to the regulation of LGR-1. The results show that IL- $1 \alpha$, IL-1 $\beta$, IL- 8 and CXCL-1/2 all increased significantly after TP1804 challenge which has basically matched the results of some research reports. The activation expression of IL- $1 \beta$ is closely related to the formation of the upstream 
inflammatory protein ASC/NLRP3/caspase-1 complex. The expression of IL-1 $\beta$ is directly proportional to the expression of inflammasomes.

Claudin-1, Occludin, and ZO-1 are three representative tight junction proteins used to detect the disruptive effect of T. pyogenes on BEECs. One of the key functions is to maintain adjacent cells close enough to each other to avoid the free passage of microorganisms across the paracellular space $[59,60]$. Through our experiment, it is easily to conclude that T. pyogenes adheres to the cell surface in the initial stage of invading cells and then causes inflammatory response activated and destroys the tight connection of cells, thereby further damaging the cell integrity and functionality. The tight connection between the endometrial epithelial cells in direct contact with the uterine cavity and the mucus in the uterine cavity together form the protective layer of the uterus. $T$. pyogenes infection caused damage to tight junctions and apoptosis and shedding of epithelial cells leading to postpartum endometritis.

At present, the use of probiotic instead of antibiotics to treat bacterial infections has become a research hot spot. Based on the previous research in our lab, a commercial probiotic LGR-1 isolated from female vagina was used to inhibit and alleviate the damage of BEECs caused by $T$. pyogenes in this study. It may be because the surface protein component of LGR-1 can bind to the receptors that identified in the bacterial cell extracts as a glycolipid-binding protein [61,62] and compete for preemption of adhesion sites to reduce the damage by inhibiting the colonization of purulent cryptic bacteria on the surface of BEECs. The results of western blotting of Claudin-1, Occludin, and ZO-1 and the observation under a light microscope indicate that LGR-1 significantly alleviated the damage and effectively protected the cell structure from the infection of T. pyogenes and reduced the cell death rate. Quantitative detection of the expression levels of tight junction proteins of BEECs markly reflects whether the physical barrier structure of epithelial cells is firm.

The western blotting results are verified by immunofluorescence results and the integrity of tight junction proteins was observed more intuitively. After the tight junction proteins of the cells were destroyed by TP1804, tight junction proteins were unable to form continuous protection around cells and other parts of BEECs were further damaged by bacteria and eventually led to cell death. However, in LGR-1 protected cells, the condition of ZO-1 protein was significantly improved and the cell structure was relatively complete. This protective effect may be due to the adhesion of LGR-1, which makes it compete with TP1804 and reduce the colonization of TP1804 on the surface of BEECs. LGR-1 pre-incubation reduces the damage of BEECs and the destruction of tight junction proteins between cells caused by TP1804, thereby protecting the endometrium and reducing the endometritis incidence.

Scanning electron microscopy and transmission electron microscopy were used to observe the ultrastructure of the surface and interior of different treated cells. Under transmission electron microscopy, destruction of mitochondria, circularization of the endoplasmic reticulum, vacuole-like changes in the nuclei, and blurred nuclear membrane boundaries were observed in BEECs infected by TP1804 after $9 \mathrm{~h}$. The results of western blotting showed the increased expression of BAX, cytochrome $c$, and caspase-3 p19 proteins but the decreased expression of Bcl-2 protein after $T$. pyogenes infection. Bcl-2 can form dimers with pro-apoptotic Bax. The relative amount of Bax is higher than Bcl-2, thereby promoting cell death. These phenomena proved that BEECs have undergone severe apoptosis during T. pyogenes infection. However, LGR-1 pretreatment alleviated cell apoptosis. Indeed, lipopeptides of some lines of bacteria were shown to increase apoptosis [63, 64]. T. pyogenes may induce the apoptosis which is activated by caspase family pathway and LGR-1 
provides an effectively protection on apoptosis. In addition, the members of the Bcl-2 family are a group of crucial regulatory factors in apoptosis [65].

\section{Conclusions}

In conclusion, T. pyogenes is able to inhibit the expression of tight junction proteins ZO-1, Claudin-1, and Occludin, damage the tight junction structure between cells, destroy the integrity of BEECs. In addition, apoptosis induced by T. pyogenes was found after TP1804 infection. The application of LGR-1 relieves the destruction of BEECs caused by T. pyogenes and attenuates the degree of apoptosis induced by T. pyogenes. Our findings suggest that LGR-1 might be used as a new strategy for prevention and treatment of bovine postpartum endometritis. The determination of the method of administration of LGR-1 (uterine catheter administration, oral administration, etc.), dosage, and administration time requires further in vivo and in vitro studies in conjunction with the reproductive cycle of dairy cows.

\section{Patents}

Author Contributions: NL, XW, and Y-HZ conceived and designed this experiment. NL, XW, LX, M-LW, and Y-NL preformed the experiments. NL and XW analyzed and NL wrote the manuscript.

Funding: Please add: This research was funded by the National Key R\&D Program of China (grant number 2017YFD0502200), the National Natural Science Foundation of China (grant number 31873034), and the Program for the Beijing Dairy Industry Innovation Team (Beijing, China).

Conflicts of Interest: The authors declare the statement of interests with no conflict.

\section{References}

1. Crowe, M.A., Williams, E.J. Triennial Lactation Symposium: Effects of stress on postpartum reproduction in dairy cows. J. Anim. Sci., 2012, 90, 1722-1727.

2. Adnane, M., Chapwanya, A., Kaidi, R., Meade, K.G., O'Farrelly, C. Profiling inflammatory biomarkers in cervico-vaginal mucus (CVM) postpartum: Potential early indicators of bovine clinical endometritis? Theriogenology, 2017, 103, 117-122.

3. LeBlanc, S.J., Duffield, T.F., Leslie, K.E., Bateman, K.G., Keefe, G.P., Walton, J.S., Johnson, W.H. Defining and diagnosing postpartum clinical endometritis and its impact on reproductive performance in dairy cows. J. Dairy Sci., 2002, 85, 2223-2236.

4. Sheldon, I.M., Lewis, G.S., LeBlanc, S., Gilbert, R.O. Defining postpartum uterine disease in cattle. Theriogenology, 2006, 65, 1516-1530.

5. Williams, E.J., Fischer, D.P., Pfeiffer, D.U., England, G.C., Noakes, D.E., Dobson, H., Sheldon, I.M. Clinical evaluation of postpartum vaginal mucus reflects uterine bacterial infection and the immune response in cattle. Theriogenology, 2005, 63, 102-117.

6. Sheldon, I.M., Rycroft, A.N., Dogan, B., Craven, M., Bromfield, J.J., Chandler, A., Roberts, M.H., Price S.B., Gilbert, R.O., Simpson, K.W. Specific strains of Escherichia coli are pathogenic for the endometrium of cattle and cause pelvic inflammatory disease in cattle and mice. PloS, 2010, one 5, e9192.

7. Machado, V.S., Oikonomou, G., Bicalho, M.L., Knauer, W.A., Gilbert, R., Bicalho, R.C. Investigation of postpartum dairy cows' uterine microbial diversity using metagenomic pyrosequencing of the 16S rRNA gene. Vet. Microbiol., 2012, 159, 460-469.

8. Wagener, K., Prunner, I., Pothmann, H., Drillich, M., Ehling-Schulz, M. Diversity and health status specific fluctuations of intrauterine microbial communities in postpartum dairy cows. Vet. Microbiol., 2015, $175,286-293$. 
9. Santos, T.M., Caixeta, L.S., Machado, V.S., Rauf, A.K., Gilbert, R.O., Bicalho, R.C. Antimicrobial resistance and presence of virulence factor genes in Arcanobacterium pyogenes isolated from the uterus of postpartum dairy cows. Vete. Microbiol., 2010, 145, 84-89.

10. Zhang, D., Zhao, J., Wang, Q., Liu, Y., Tian, C., Zhao, Y., Yu, L., Liu, M. Trueperella pyogenes isolated from dairy cows with endometritis in Inner Mongolia, China: Tetracycline susceptibility and tetracycline-resistance gene distribution. Microb. Pathogenesis, 2017, 105, 51-56.

11. Sheldon I.M., Cronin J., Goetze L., Donofrio G., Schuberth H.J. Defining postpartum uterine disease and the mechanisms of infection and immunity in the female reproductive tract in cattle. Biol. Reprod., 2009, 81, 1025-1032.

12. Bicalho, M.L.S., Lima, S., Higgins, C.H., Machado, V.S., Lima, F.S., Bicalho, R.C. Genetic and functional analysis of the bovine uterine microbiota. Part II: Purulent vaginal discharge versus healthy cows. J. Dairy Sci., 2017, 100, 3863-3874.

13. Sheldon, I.M., Noakes, D.E., Rycroft, A.N., Pfeiffer, D.U., Dobson, H. Influence of uterine bacterial contamination after parturition on ovarian dominant follicle selection and follicle growth and function in cattle. Reproduction, 2002, 123, 837-845.

14. Kavitha, K., Latha, R., Udayashankar, C., Jayanthi, K., Oudeacoumar, P. Three cases of Arcanobacterium pyogenes-associated soft tissue infection. J. Medical. Microbiol., 2010, 59, 736-739.

15. Levy, C.E., Pedro, R.J., Von Nowakonski, A., Holanda, L.M., Brocchi, M., Ramo, M.C. Arcanobacterium pyogenes sepsis in farmer, Brazil. Emerg. Infect. Dis., 2009, 15, 1131-1132.

16. Amos, M.R., Healey, G.D., Goldstone, R.J., Mahan, S.M., Duvel, A., Schuberth, H.J., Sandra, Olivier, Zieger, Peter, Dieuzy-Labaye, I., Smith, D.G.E., Sheldon, I.M. Differential endometrial cell sensitivity to a cholesterol-dependent cytolysin links Trueperella pyogenes to uterine disease in cattle. Biol. Reprod., 2014, 90,54 .

17. Lima, F.S., Greco, L.F., Bisinotto, R.S., Ribeiro, E.S., Martinez, N.M., Thatcher, W.W., Santos, J.E.P., Reinhard, M.K., Galvao, K.N. Effects of intrauterine infusion of Trueperella pyogenes on endometrial mRNA expression of proinflammatory cytokines and luteolytic cascade genes and their association with luteal life span in dairy cows. Theriogenology, 2015, 84, 1263-1272.

18. Ibrahim, M., Peter, S., Wagener, K., Drillich, M., Ehling-Schulz, M., Einspanier, R., Gabler, C. Bovine Endometrial Epithelial Cells Scale Their Pro-inflammatory Response In vitro to Pathogenic Trueperella pyogenes Isolated from the Bovine Uterus in a Strain-Specific Manner. Front. Cell. Infect. Mi., 2017, 7, 264.

19. Guo, H., Callaway, J.B., Ting, J.P. Inflammasomes: mechanism of action, role in disease, and therapeutics. Nat. Med., 2015, 21, 677-687.

20. Sutterwala, F.S., Haasken, S., Cassel, S.L. Mechanism of NLRP3 inflammasome activation. Ann. NY Acad. Sci., 2014, 1319, 82-95.

21. Ratsimandresy, R.A., Dorfleutner, A., Stehlik, C. An Update on PYRIN Domain-Containing Pattern Recognition Receptors: From Immunity to Pathology. Front. Immunol., 2013, 4, 440.

22. Rathinam, V.A., Vanaja, S.K., Fitzgerald, K.A. (2012). Regulation of inflammasome signaling. Nat. Immunol. 13, 333-342. doi: 10.1038/ni.2237

23. Neudecker, V., Haneklaus, M., Jensen, O., Khailova, L., Masterson, J.C., Tye, H., Biette, K., Jedlicka, P., Brodsky, K., Gerich M.E., Mack, M., Robertson, A.A.B., Cooper, M.A., Furuta, G.T., Dinarello, C.A., O’Neill L.A., Eltzschig, H.K., Masters, S.L., McNamee, E.N. Myeloid-derived miR-223 regulates intestinal inflammation via repression of the NLRP3 inflammasome. J. Exp. Med., 2017, 214, 1737-1752.

24. Davis, B.K., Wen, H., Ting, J.P. The inflammasome NLRs in immunity, inflammation, and associated diseases. Annu. Rev. Immunol., 2011, 29, 707-735. 
25. Zhao, G., Jiang, K., Yang, Y., Zhang, T., Wu, H., Shaukat, A., Qiu, C., Deng, G. The Potential Therapeutic Role of miR-223 in Bovine Endometritis by Targeting the NLRP3 Inflammasome. Front. Immunol., 2018, 9 , 1916.

26. Lamkanfi, M., Dixit, V.M. Inflammasomes and their roles in health and disease. Annu. Rev. Cell Dev. Bi., 2012, 28, 137-161.

27. Strowig, T., Henao-Mejia, J., Elinav, E., Flavell, R. Inflammasomes in health and disease. Nature, 2012, 481, 278-286.

28. Betanzos, A., Zanatta, D., Banuelos, C., Hernandez-Nava, E., Cuellar, P., Orozco, E. Epithelial Cells Expressing EhADH, An Entamoeba histolytica Adhesin, Exhibit Increased Tight Junction Proteins. Front. Cell. Infect. Mi., 2018, 8, 340.

29. Tsukita, S., Furuse, M., Itoh, M. Multifunctional strands in tight junctions. Nat. Rev. Mol. Cell Bio., 2001, 2, 285-293.

30. Anderson, J.M., Van Itallie, C.M. Tight junctions: closing in on the seal. Curr. Biol., 1999, 9, R922-924.

31. Luo, X., Guo, L., Zhang, J., Xu, Y., Gu, W., Feng, L., Wang, Y. Tight Junction Protein Occludin Is a Porcine Epidemic Diarrhea Virus Entry Factor. J. Virol., 2017, 91, e00202-17.

32. Hartsock, A., Nelson, W.J. Adherens and tight junctions: structure, function and connections to the actin cytoskeleton. Biochimica et biophysica acta, 2008, 1778, 660-669.

33. Xia, Z., Huang, L., Yin, P., Liu, F., Liu, Y., Zhang, Z. L-Arginine alleviates heat stress-induced intestinal epithelial barrier damage by promoting expression of tight junction proteins via the AMPK pathway. Mol. Biol. Rep., 2019, 46, 6435-6451.

34. Martinez-Palomo, A., Gonzalez-Robles, A., Chavez, B., Orozco, E., Fernandez-Castelo, S., Cervantes, A. Structural bases of the cytolytic mechanisms of Entamoeba histolytica. J. Protozoology, 1985, 32, 166-175.

35. Leroy, A., Lauwaet, T., De Bruyne, G., Cornelissen, M., Mareel, M. Entamoeba histolytica disturbs the tight junction complex in human enteric T84 cell layers. FASEB j., 2000, 14, 1139-1146.

36. Betanzos, A., Javier-Reyna, R., Garcia-Rivera, G., Banuelos, C., Gonzalez-Mariscal, L., Schnoor, M., et al. (2013). The EhCPADH112 complex of Entamoeba histolytica interacts with tight junction proteins occludin and claudin-1 to produce epithelial damage. PloS one, 2013, 8, e65100.

37. Fuchs, Y., Steller, H. Programmed cell death in animal development and disease. Cell, 2011, 147, 742-758.

38. Pistritto, G., Trisciuoglio, D., Ceci, C., Garufi, A., D'Orazi, G. Apoptosis as anticancer mechanism: function and dysfunction of its modulators and targeted therapeutic strategies. Aging, 2016, 8, 603-619.

39. Hacker, G. The morphology of apoptosis. Cell and Tissue Research, 2000, 301, 5-17.

40. Saraste, A., Pulkki, K. Morphologic and biochemical hallmarks of apoptosis. Cardiovasc. Res., 2000, 45, 528-537.

41. Elmore, S. Apoptosis: a review of programmed cell death. Toxicol. Pathol., 2007, 35, 495-516.

42. Norbury, C.J., Hickson, I.D. Cellular responses to DNA damage. Ann. Rev. Pharmacol., 2001, 41, 367-401.

43. McArthur, K., Chappaz, S., Kile, B.T. Apoptosis in megakaryocytes and platelets: the life and death of a lineage. Blood, 2018, 131, 605-610.

44. Suen, D.F., Norris, K.L., Youle, R.J. Mitochondrial dynamics and apoptosis. Gene. Dev., 2008, 22, 1577-1590.

45. Jost, B.H., Field, A.C., Trinh, H.T., Songer, J.G., Billington, S.J. Tylosin resistance in Arcanobacterium pyogenes is encoded by an erm $X$ determinant. Antimicrob. Agents Ch., 2003, 47, 3519-3524.

46. Yu, J., Zhu, Y.H., Yang, G.Y., Zhang, W., Zhou, D., Su, J.H., Wang, J.F. Anti-inflammatory capacity of Lactobacillus rhamnosus GG in monophasic variant Salmonella infected piglets is correlated with impeding NLRP6-mediated host inflammatory responses. Vet. Microbiol., 2017, 210, 91-100. 
47. Zhang, W., Wu, Q., Zhu, Y., Yang, G., Yu, J., Wang, J., Ji, H. Probiotic Lactobacillus rhamnosus GG Induces Alterations in Ileal Microbiota With Associated CD3(-)CD19(-)T-bet(+)IFNgamma(+/-) Cell Subset Homeostasis in Pigs Challenged With Salmonella enterica Serovar 4,[5],12:i. Front. Microbiol., 2019, $10,977$.

48. Wu, Q., Liu, M.C., Yang, J., Wang, J.F., Zhu, Y.H. Lactobacillus rhamnosus GR-1 Ameliorates Escherichia coli-Induced Inflammation and Cell Damage via Attenuation of ASC-Independent NLRP3 Inflammasome Activation. Appl. Environ. Microb., 2016, 82, 1173-1182.

49. Fortier, M.A., Guilbault, L.A., Grasso, F. Specific properties of epithelial and stromal cells from the endometrium of cows. J. Reprod. Fert., 1988, 83, 239-248.

50. Lötscher J., Balmer M.L. Sensing between reactions - how the metabolic microenvironment shapes immunity. Clin. Exp. Immunol., 2019, 2, 161-169.

51. Hoque, R., Farooq,A., Ghani, A., Gorelick, F., Mehal, W.Z. Lactate reduces liver and pancreatic injury in Toll-like receptor- and inflammasome-mediated inflammation via GPR81-mediated suppression of innate immunity. Gastroenterology, 2014, 146, 1763-1774.

52. Drillich, M., Tesfaye, D., Rings, F., Schellander, K., Heuwieser, W., Hoelker, M. Effects of polymorphonuclear neutrophile infiltration into the endometrial environment on embryonic development in superovulated cows. Theriogenology, 2012, 77, 570-578.

53. Wagener, K., Pothmann, H., Prunner, I., Peter, S., Erber, R., Aurich, C. Drillich M., Gabler, C. Endometrial mRNA expression of selected pro-inflammatory factors and mucins in repeat breeder cows with and without subclinical endometritis. Theriogenology, 2017, 90, 237-244.

54. Rainard, P., Riollet, C., Berthon, P., Cunha, P., Fromageau, A., Rossignol, C. The chemokine CXCL3 is responsible for the constitutive chemotactic activity of bovine milk for neutrophils. Mol. Immunol., 2008, 45, 4020-4027.

55. Jo, E.K., Kim, J.K., Shin, D.M., Sasakawa, C. Molecular mechanisms regulating NLRP3 inflammasome activation. Cell. Mol. Immunol., 2016, 13, 148-159.

56. Shi, Y. Caspase activation: revisiting the induced proximity model. Cell, 2004, 117, 855-858.

57. Weigt, S.S., Palchevskiy, V., Belperio, J.A. Inflammasomes and IL-1 biology in the pathogenesis of allograft dysfunction. J. Clin. Invest., 2017, 127, 2022-2029.

58. Wu, Q., Zhu, Y.H., Xu, J., Liu, X., Duan, C., Wang, M.J., Wang J.F. Lactobacillus rhamnosus GR-1 Ameliorates Escherichia coli-Induced Activation of NLRP3 and NLRC4 Inflammasomes With Differential Requirement for ASC. Front. Microbiol., 2018, 9, 1661.

59. Shen, L. (2012). Tight junctions on the move: molecular mechanisms for epithelial barrier regulation. Annals of the New York Academy of Sciences, 2012, 1258, 9-18.

60. Steed, E., Balda, M.S., Matter, K. Dynamics and functions of tight junctions. Trends Cell Biol., 2010, 20, 142-149.

61. Mukai, T., Asasaka, T., Sato, E., Mori, K., Matsumoto, M., Ohori, H. Inhibition of binding of Helicobacter pylori to the glycolipid receptors by probiotic Lactobacillus reuteri. FEMS Immunol. Med. Mic., 2002, 32, 105-110.

62. Mukai, T., Kaneko, S., Matsumoto, M., Ohori, H. (2004). Binding of Bifidobacterium bifidum and Lactobacillus reuteri to the carbohydrate moieties of intestinal glycolipids recognized by peanut agglutinin. Int. J. food Microbiol., 2004, 90, 357-362.

63. Aliprantis, A.O., Yang, R.B., Mark, M.R., Suggett, S., Devaux, B., Radolf, J.D., Klimpel G.R., Godowski P., Zychlinsky A. Cell activation and apoptosis by bacterial lipoproteins through toll-like receptor-2. Science, $1999,285,736-739$. 
64. Siemieniuch, M.J., Szostek, A.Z., Gajos, K., Kozdrowski, R., Nowak, M., Okuda, K. Type of Inflammation Differentially Affects Expression of Interleukin 1beta and 6, Tumor Necrosis Factor-alpha and Toll-Like Receptors in Subclinical Endometritis in Mares. PloS one, 2016, 11, e0154934.

65. Fan, T.J., Han, L.H., Cong, R.S., Liang, J. Caspase family proteases and apoptosis. Acta Bioch. Bioph. Sin. 2005, 37, 719-727. 